\title{
Brexit na perspectiva do Path Dependency
}

\author{
Brexit from the perspective of Path Dependency
}

\section{Giorgio Romano Schutte}

Resumo Esta pesquisa analisou o Brexit em uma perspectiva histórica, focando a conturbada relação entre a Europa continental e o Reino Unido ao longo do século XX, com ênfase no período pós Segunda Guerra Mundial. Foi utilizado o conceito de path dependency para argumentar sobre o papel de fatores históricos e decisões do passado, embora tomados em outras circunstâncias, ainda com força para influenciar o presente, para entender o Brexit. A premissa básica que será apresentada no ensaio é que o Reino Unido nunca participou de fato da ideia da Europa e sempre se viu como um país diferente por sua história e seu papel no mundo. Quando entrou, foi com uma perna só, a outra sempre ficou atrás, inclusive devido às especificidades de sua estrutura econômica herdada do passado, em particular no que diz respeito à agricultura. Desta forma, defende-se que, embora longe de ter sido inevitável, se tratou de um fenômeno limitado ao Reino Unido que tinha pouquíssima probabilidade de se repetir em outros países da União Europeia.

Palavras-chave Brexit; Path Dependency; Integração Europeia; Reino Unido.

Abstract This research analyzed Brexit in a historical perspective, focusing on the specific relation between continental Europe and the United Kingdom during the $X X$ Century, with emphasis on the period after the Second World War. The concept of path dependency was used to explore the historical factors and decision taken in the past, which, although in different circumstances, still influence the present and are useful to understand the Brexit. The basic premises that will be presented is that the UK in fact never identified itself with the idea of Europe as developed by the Continental members. It always saw itself as a country with a different history and a different role in the world. When it got its membership, the country only entered with one leg, keeping the other always outside. This also reflects the different configuration of its economic structure, specifically with regard to agriculture. By this, although not at all inevitable, it will be defended that we are dealing with a very British phenomenon which had extremely little chance to be repeated by other countries of the European Union.

Keywords Brexit; Path Dependency; European integration; United Kingdom.

a Professor de Relações Internacionais da UFABC. 


\section{INTRODUÇÃO}

Em junho 2016, foi realizado o segundo referendum sobre a permanência do Reino Unido na União Europeia e, para surpresa da maioria dos analistas políticos e econômicos, o Brexit ganhou. Em seguida, sugiram especulações sobre a possibilidade de este resultado ser seguido por outros países membros. De forma implícita se sugere, nesse caso, que o resultado teria sido determinado por fatores conjunturais, como a migração e o desdobramento da crise financeira global iniciada em 2008. Ou, na chave de uma inevitabilidade dado a crise do regime macroeconômico neoliberal (BLyth; Matтhiss, 2017). Neste ensaio, pretende-se defender a tese de que o resultado deve ser compreendido e analisado no contexto da trajetória específica da relação do Reino Unido (RU) com a União Europeia (UE), seguindo uma abordagem de path dependency (MAноneY, 2000; SEWELL,1990; Nоотевоом, 1997). A conjuntura política e econômica interagiu com esse contexto específico. A abordagem do path dependency não sugere uma teleologia no sentido de que a sequência dos eventos levaria automaticamente a esse desfecho. $\mathrm{O}$ que se procura defender é que o voto pelo Brexit, embora não pode ser interpretado como um resultado lógico se analisada a sequência dos acontecimentos, dialoga com uma trajetória histórica que remonta à negação do país em participar do Plano Schuman no início da década de 1950. Nesse sentido, o Brexit aparece como uma história muito britânica, com pouca probabilidade de ser seguida nos países membros do continente. $\mathrm{O}$ ensaio é dividido em cinco seções contando com esta introdução. Na segunda seção será feita uma apresentação da abordagem do path dependency. Na terceira, uma análise do período até a entrada na Comunidade Econômica Europeia (CEE), em 1973. Na quarta, focamos na relação como membro e tentamos mostrar a continuidade de um distanciamento baseado em uma noção de diferenças profundas de ordem histórico-cultural, institucional (o parlamentarismo) e econômica. Concluímos com algumas considerações finais na quinta seção. Para a reconstrução da trajetória do RU perante o processo de integração Europeia foram utilizados os trabalhos de Young (1998), Wall (2008), Bogdanor (2014), Camps (2017), Gowland \& Tumer (2000) e Tatcher (1995, 2002). Neste artigo não serão abordadas as dinâmicas políticas e dos movimentos separatistas da Escócia, Irlanda do Norte e Pais de Gales, que mereceriam uma abordagem específica.

\section{PATH DEPENDENCY}

A abordagem de path dependency surgiu na história econômica para explicar como escolhas por determinadas tecnologias no passado determinam as escolhas subsequentes, mesmo na presença de alternativas aparentemente mais compe- 
titivas, elaborando uma interpretação alternativa ao paradigma neoclássico da escolha racional considerada a-histórica. Depois, ela ganhou força na sociologia histórica e nos estudos das relações internacionais. Uma referência importante para esse debate é Mahoney (2000), que tentou organizar melhor o valor adicional dessa abordagem, além de uma simples busca de causas remotas para explicar um resultado presente. Ele sugere que é preciso identificar um evento contingente no passado que provocou o início de uma trajetória específica. Nas palavras do autor, não basta "tracing a given outcome back to a particular set of historical events", mas é também preciso demonstrar que estes eventos "are themselves contigent occurrences" (MAHONEY, 2000, p. 507). Assim, poderia ser demonstrado a partir daquele evento que a história tomou um rumo que poderia ter sido diferente. Subsequentemente, fica cada vez mais difícil fugir da lógica que se impôs. Escolhas passadas vão limitando o espaço e o escopo para escolhas futuras. Pressupõe-se, portanto, o funcionamento de mecanismos de auto-reforço (self-reinforcement). Outros autores apresentam uma definição menos complexa desse conceito. Sewell (1990) identificou path dependent simplesmente como: "what happened at an earlier point in time will affect the possible outcome of a sequence of events occurring at a later point in time" (SEwELL, 1990, p. 16). Nooteboom (1997), na mesma linha: “...directions for future development are foreclosed or inhibited by directions taken in past development" (p.57). A ideia básica é que decisões tomadas no passado influenciam as alternativas em futuros eventos, sugerindo, sobretudo quando aplicado à história econômica, certa inércia. Ou seja, “...once a particular option is selected it becomes progressively more difficult to return to the initial point when multiple alternatives were still available" (MAHONEY, 2000, p. 513). Mas, como foi mencionado, seria crucial identificar essa "particular option".

Mas para além de identificar o evento contingente, cabe também explicar os mecanismos que reproduzem a influência subsequente dessa escolha. Mahoney apresentou quatro tipologias de abordagens para resolver esse problema. A primeira seria a utilitarista: as instituições podem ser menos eficientes do que as alternativas originais, mas uma vez estabelecida a trajetória, o benefício de continuar nesta opção pode ser maior do que o de alterar a rota, embora possa haver mudanças de rumo diante de pressões competitivas. A segunda seria funcionalista: embora possa ser menos funcional quando comparado às alternativas iniciais, uma vez estabelecida a trajetória, essa se torna funcional para a manutenção do sistema. Nesse caso, pode haver um choque externo que obrigue a uma alteração de rumo. A terceira dialoga com a teoria de elites: a escolha inicial levou ao poder, ou reforçou a posição de uma fração da elite que, para a reprodução da sua posição, 
tende a insistir na trajetória. A alteração de rumo será dada, nesse caso, pelo enfraquecimento dessa fração e o fortalecimento da elite que se beneficia dele. Nesse caso, a reprodução institucional é conflitiva e a dinâmica de potencial mudança estaria implícita. Por último, pode-se enfatizar o fator de legitimação. Embora o caminho escolhido possa ser menos consistente com os valores da sociedade do que as alternativas existentes inicialmente, a sua reprodução aparece agora como moralmente justa e apropriada. Pode-se identificar, aqui, um elemento de inércia ideológica ou cognitiva. A mudança de rumo seria dada com mudanças culturais e de valores e fica, portanto, evidenciada a força do status quo. Em todos os casos, não há necessariamente uma reprodução do mesmo caminho. Pode haver uma sequencia reativa, "reactive sequences" (MAHONEY, 2000, p. 526). Nesse caso, registram-se contrarreações que provocam uma trajetória não-linear, mas cuja margem de opção e ação continua sendo influenciada fortemente pelas decisões tomadas no passado, em particular na ocasião do evento contingente que daria origem à trajetória. Nas palavras de Costa (2015):

em vez da reprodução estável de um resultado particular ao longo do tempo, o que se tem são, antes, dinâmicas de reação e contrarreação em que cada evento na sequência é tanto uma reação a eventos antecedentes quanto uma causa para eventos subsequentes.

Usando a proposta de Mahoney apresentada acima, caberia identificar o evento contingente que iniciou a trajetória particular da relação entre o RU e a UE, que é, na nossa hipótese, a decisão de não participar das negociações em torno do Plano Schuman. Com isso, o RU não participou da criação e consolidação da Comunidade e acabou entrando no bloco apenas 16 anos depois.

Uma divergência da abordagem proposta por Mahoney é que, na nossa visão, uma mudança de rota devido a pressões conjunturais não necessariamente gera uma nova síntese. Fatores fortemente influenciados pela trajetória passada podem continuar operantes. E, embora de forma marginalizada das decisões estratégicas, mantêm um potencial de influenciar estas decisões e, em determinadas circunstâncias, sobrepor-se novamente, atuando como fator decisivo. Em síntese, a força do euroceticismo britânico parecia estar neutralizada e controlada a partir do governo Blair, mas, na conjuntura em torno do segundo referendum, conseguiu se sobrepor e fazer prevalecer valores e escolhas que pareciam ter sido superados.

Isso não significa que a influência de fatores conjunturais - no nosso estudo de caso, principalmente a questão da migração e os desdobramentos socioeconô- 
micos da crise financeira global de 2008- estaria subordinada ou seria refém das escolhas do passado. Pode haver um "coming together - or temporal intersection - of separately determined sequences" (MAHONEY, 2000, p. 527). O resultado será imprevisível e exige a análise de eventos que são essenciais para a ocorrência dessa interseção e das ações subsequentes.

Ou seja, o Brexit foi um 'resultado possível' do impacto dos fatores conjunturais em uma realidade marcada por uma frágil relação histórica com a integração europeia. Os mesmos fatores conjunturais dificilmente poderiam produzir igual resultado em outro contexto. Ao mesmo tempo, sem os impactos conjunturais, a trajetória histórica não teria levado ao desfecho do Brexit. Com isso, este artigo pretende contribuir com o entendimento da especificidade do Brexit, além dos fatores conjunturais.

\section{ENTRAR OU FICAR DE FORA: EIS A QUESTÃO}

Terminada a Segunda Guerra Mundial, o Reino Unido se viu como uma das três potências mundiais. De fato, a moldagem do novo mundo estava sendo feita pelos líderes dos EUA, da União Soviética e do RU, simbolizado, até as eleições de julho de 1945, pela participação de Winston Churchill como um dos líderes do mundo pós-nazista ao lado de Joseph Stalin e Franklin D. Roosevelt. Nesse contexto, o RU recuperou, em um primeiro momento, seu vasto império e tinha motivos de sobra para se sentir muito diferente dos países da Europa continental. Afinal foi o único que resistiu à agressão nazista. Grande parte da elite econômica e política do RU imaginava ser possível continuar como uma potência global baseada na suposta força econômica da Commonwealth, na Libra Esterlina como moeda de reserva mundial e na sua força militar. Não fazia parte do debate nacional, nesse momento, a imagem de que o país estaria condenado a deixar de ser uma potência mundial. Young, no seu livro, This Blessed Plot, cita em várias passagens a ambivalência do próprio Churchill que, em 1930, escreve um artigo no The Saturday Evening Post defendendo a criação dos Estados Unidos da Europa para solucionar o conflito entre França e Alemanha e criar as condições de uma economia de escala a exemplo dos EUA (Young, 1998, p. 10) e, durante a guerra, apontava a União Soviética como principal ameaça contra o qual a Europa deveria se unir. A confusão estava no papel do RU nesse processo: "We are with Europe, but not of it. We are linked, but not comprised" (Young, 1998, p. 13). Nesse espírito, já no governo trabalhista de Attlee, houve uma participação nos primeiros esforços de cooperação com a Europa. Primeiro, no Tratado de Bruxelas de 1948, que pode ser visto como um primeiro passo rumo à formação da Organização do Tratado do Atlântico Norte (OTAN) e 
que envolvia os países do Benelux, a França e o RU. Nesse momento, os primeiros já queriam avançar numa cooperação, para além do âmbito militar, mas o RU bloqueou esse caminho. No ano seguinte, houve a criação do Conselho da Europa com sede em Estrasburgo (França). O RU participou ativamente desse processo, mas usou sua influência para garantir que o órgão tivesse pouca influência ${ }^{1}$. Além disso, para o governo dos EUA, o Plano Marshall deveria ser acompanhando de acordos de livre comércio entre os países partícipes e, para isso, tinha feito a proposta de uma União Aduaneira na Europa ocidental que, naquele momento, no entanto, não saiu do papel devido ao veto do $\mathrm{RU}^{2}$. Além da preocupação com a Commonwealth, estava já muito presente entre os britânicos uma suspeita contra instituições europeias, compartilhada por diversas forças políticas³.

Em 1950, inspirado pelas ideias de Jean Monnet, o então ministro de Relações Exteriores da França, Robert Schuman, lançou um plano para a integração das indústrias de carvão e aço e a criação de uma autoridade supranacional, no que ficou conhecido como Plano Schuman. Os primeiros ministros da Alemanha e da Itália, respectivamente Konrad Adenauer e Alcide de Gaspari, abraçaram essa proposta. Esses três líderes, todos católicos e fluentes em alemão, insistiram na participação do RU pelo peso da sua indústria de carvão e aço e pela perspectiva da integração que isso poderia provocar em outras áreas. É justamente aqui que identificamos uma decisão que pode ser caracterizada como um "evento contingente" que irá determinar os passos subsequentes. O governo trabalhista negou participar do Plano por dois motivos. Primeiro, o governo tinha nacionalizado as indústrias de aço e carvão justamente com o argumento de implementar uma política setorial soberana e tinha pavor de perder esse poder para uma instância supranacional. Segundo, porque havia uma sensação de irreversibilidade de um processo que caminhava para um federalismo. Ao mesmo tempo, o RU era totalmente a favor de incorporar o crescimento da Alemanha a uma cooperação europeia e estimulou a França a continuar com a iniciativa. No Parlamento, Churchill insistiu ainda na conveniência em participar com o argumento de que não seria possível imaginar

1 Não obstante, as forças políticas do continente com orientação mais federalista conseguiram a Convenção Europeia dos Direitos Humanos e o Tribunal Europeu dos Direitos Humanos.

2 Como alternativa, o Plano Marshall acabou sendo coordenado por uma instituição puramente intergovernamental, a Organização Econômica Europeia de Cooperação (OEEC na sigla inglesa), que seria transformada mais tarde na OCDE.

3 Curiosamente, quem defendia a perspectiva federativa europeia era a esquerda da fração "Keep Left", já com Michael Foot, por uma inspiração antiamericana. A Europa poderia funcionar como uma terceira via (Young, 2000, p. 41). Mais tarde, a esquerda do Labour iria ser uma das forças mais antieuropeias por considerar a Europa uma proposta liberalizante que diminuiria a capacidade dos estados nacionais de domesticar o capitalismo. 
discussões estratégicas no continente sem a presença britânica (Young, 2000, p. 66). Sem dúvida, o RU nesse momento tinha a liderança para, ao participar, influenciar a discussão, reforçando seu caráter intergovernamental e impedindo qualquer avanço significativo de supranacionalidade (Bogdanor, 2014a). Assim, em abril de 1951, foi lançada a Comunidade de Aço e Carvão com Monnet na presidência, sem a participação britânica. Na ausência de forças políticas que defendessem a participação no Plano Schuman, o assunto sequer entrou na campanha eleitoral, em outubro de 1951, e o novo governo Churchill não fez nenhum movimento para alterar essa política. A revista liberal The Economist foi voz solitária ao defender uma política de integração ${ }^{4}$.

A decisão de não participar do Plano Schuman influenciou os eventos seguintes. Os seis países da Comunidade de Aço e Carvão se reuniram em um encontro histórico em Messina (Itália), em 1955, para discutir próximos passos e inciativas em outros setores. Não sendo parte da Comunidade, o Reino Unido foi informado, mas não convidado. Esse novo fato reabriu a discussão no governo se era melhor participar para frear as forças federalistas no continente ou ficar de fora para defender seu próprio caminho. Havia ainda no governo britânico um ceticismo enorme sobre a viabilidade das propostas, porque se imaginava que a força do nacionalismo, sobretudo da França, fosse capaz de impedir qualquer avanço significativo. Um grave erro de avaliação que iria se repetir com relação ao Tratado de Maastricht, em particular à União Monetária Europeia. Há de se enfatizar que, nesse momento, o RU ainda teria sido o primo entre pares, com capacidade de direcionar os esforços para uma área de livre comércio com exceções para seu comércio com a Commonwealth.

Em pouco tempo, o mundo mudou radicalmente, mas, agora, as opções britânicas estavam limitadas devido às escolhas que conduziram o RU a um beco sem saída. Em primeiro lugar, contrariando a aposta do governo britânico, o Tratado de Roma foi firmado em março 1957, menos de seis meses depois de o RU ter passado pela humilhação do conflito de Suez (novembro de 1956), quando foi obrigado a aceitar que acabara o império britânico. Um ano depois, em 1958, a Alemanha registrou um Produto Interno Bruto (PIB) superior ao do RU e o mesmo valia para suas exportações (Young, 2000, p.105-106). Na França, o episódio do Canal de Suez reforçou a aposta na opção europeia e, de certa forma, no governo britânico

4 Cabe enfatizar que os EUA ao longo de todo esse período inicial expressou de várias formas seu interesse em ver a liderança britânica no processo de integração, sobretudo no contexto da reindustrialização e do rearmamento da Alemanha. 
e, em particular no Foreign Office, começou-se, finalmente, uma reflexão sobre a necessidade de se adequar à nova realidade.

Nesse contexto, o governo britânico lançou um plano, conhecido como Plano G, para retomar o tempo perdido. Só que subestimou, de um lado, a perda da sua força relativa na Europa e, de outro, os avanços alcançados no processo de integração dos seis países do continente, liderado agora pela França, com Charles de Gaulle, a partir de 1959, na presidência. Assim, segundo o Plano G, o governo britânico imaginava possível esvaziar a Comunidade Econômica Europeia (CEE) ao propor uma área de livre comércio: a Associação Europeia de Comércio Livre (European Free Trade Agreement, EFTA). A EFTA abrangeria mais países 5 , sem coordenação política e nenhuma Tarifa Externa Comum (TEC). Além disso, a agricultura estaria fora do acordo. Analisando posteriormente essa proposta, parece inacreditável que o RU pudesse ter imaginado que ainda detinha capacidade para impor um projeto como esse aos seus aliados no continente. Mas, historicamente, foi isso que o RU fez e, como não poderia ter sido diferente, fracassou completamente ${ }^{6}$. Sugeriu ainda, por parte dos britânicos, um acordo de livre comércio entre a EFTA e a CEE, proposta também fadada ao fracasso.

O governo britânico, a essa altura, entendeu que não restavam muitas opções. Documentos internos da equipe governamental à época mostram o amadurecimento da ideia de pedir uma entrada do UK na CEE em condições especiais e com um status à parte que levasse em consideração seus interesses econômicos divergentes e sua visão política diferente. $\mathrm{E}$ foi dessa forma e nesses termos que o UK entrou em negociação com a CEE em 1960 (CAMPs, 2017). Quais eram essas diferenças econômicas? Historicamente, desde a abolição dos famosos Corn Laws em 1846, o capitalismo britânico apostou na manufatura interna e na importação de alimentos mais baratos. Com isso, seria possível, inclusive, manter o custo da mão de obra em níveis mais baixos. Essa lógica fez com que o setor agrícola fosse substancialmente menor comparado aos países do continente ${ }^{7}$ e a dependência da importação de alimentos, por conseguinte, muito maior. No continente, quem financiava a agricultura eram os consumidores na forma de preços superiores. No

5 Observamos que quatro décadas depois o RU foi entusiasta da expansão da UE incorporando o mais rápido possível o maior número de países do ex-bloco comunista para esvaziar o impacto da união monetária. Nesse caso, porém, ele estava alinhado com uma forte pressão dos EUA nessa direção.

6 A EFTA chegou a ser criada em 1960 na cidade de Estocolmo, com uma importância econômica e política muito inferior a da CEE juntando somente Portugal, Dinamarca, Noruega, Suíça, Áustria e Suécia, além do RU.

7 Na década de 1950 a força de trabalho no campo no RU era de 4\% contra 20\% na França, 25\% na Itália e 13\% na Alemanha (BogdANOR, 2014a). 
RU eram os contribuintes na forma de subsídios do governo para os agricultores britânicos. Nesse contexto, tornava-se ainda mais dramática a TEC, com a arrecadação direcionada para Bruxelas e sendo distribuída na forma de subsídios para os agricultores europeus. Assim, a Política Agrícola Comum significaria que os britânicos iriam: a) pagar mais por seus alimentos; b) arrecadar muito, mas sendo obrigados a transferir para Bruxelas para subsidiar exportações dos produtores europeus e, portanto, com pouco retorno para seus agricultores, que eram menores em número; c) prejudicar os outros membros da Commonwealth, como a Nova Zelândia, que teriam agora dificuldade de exportar para o RU. Havia uma ideia de um trade-off: o que o RU perderia na agricultura poderia ganhar com a abertura dos mercados no continente para sua manufatura. Mas quando, de fato, entrou na CEE, se viu confrontado com uma manufatura alemã mais competitiva. Assim, havia, de fato, um problema estrutural que, de uma forma ou de outra, deveria ter sido negociado. Mas se o RU tivesse participado desde o início, é evidente que teria sido mais fácil negociar esse ajuste do que depois e a partir de uma posição de fragilidade.

As diferenças políticas eram de outra ordem. O Parlamento de Westminster é considerado pelos partidos representativos como a essência da democracia e da soberania britânica. Quando surge a discussão sobre a perda de soberania, isso se refere especificamente à perda da soberania parlamentar. Na tradição política britânica, é difícil de aceitar que exista um poder que limite o do seu parlamento. Por isso, a defesa intransigente do intergovernamentalismo e a rejeição de supranacionalismo e de poder na mão de Comissão, vista essencialmente como órgão não eleito. Esta visão era compartilhada por trabalhistas e conservadores.

Depois de ter ganhado novamente as eleições em 1959, Macmillan se orientou pelo realismo, pautado no risco de perder competitividade ao ficar de fora da CEE, no fim do império britânico e, além disso, na pressão dos EUA para avançar na integração europeia. Mesmo assim, o governo entrou nas negociações com pouco entusiasmo e convicção. O mandato do Parlamento era verificar se havia condições de negociar de forma satisfatória a entrada do RU na CEE (BoGDANOR, 2014a). Essa postura hesitante e defensiva do governo iria se refletir também em uma falta de entusiasmo e um ceticismo persistente da população (Young, 2000, p. 140). Dois anos depois do início das negociações, de Gaulle declarou, em janeiro de 1963, em uma coletiva de imprensa, que o RU não estava preparado para entrar, o que foi 
interpretado como um veto ${ }^{8}$. As negociações se interromperam, contra a vontade dos demais membros da CEE, em particular da Alemanha, e Macmillan saiu da cena política. Observa-se que a oposição nessa época também estava dividida e seu líder, Hugh Gaitskell, mantinha-se ambíguo. Em um famoso discurso no congresso do Labour, em outubro 1962, no meio das negociações, misturou argumentos pró e contra, mas o tom era de ceticismo, expresso na frase que iria ficar na história politica britânica ao dizer que a entrada na CEE, do jeito que estava constituída, seria "The end of a thousand years of history". Ao invés do centro da Commonwealth, o RU se tornaria uma província da Europa. De outro lado, não haveria porque rejeitar uma entrada por princípio, só que para isso era preciso que a CEE mudasse sua estrutura. Dentro do campo dos conservadores havia uma tendência a defender uma associação de livre comércio com a CEE ao invés de tornar-se membro pleno. Young registrou que "The ideia of mere association with the Community, which has always been the ambition of Conservative politicians who wanted to have it both ways, was unacceptable" (Young, 2000, p. 173). Mas essa conclusão é questionável. Na histórica fala do General de Gaulle, ficava claro porque (tradução em inglês):

Moreover, I repeat, if the Brussels negotiations were shortly not to succeed, nothing would prevent the conclusion between the Common Market and Great Britain of an accord of association designed to safeguard exchange ${ }^{9}$.

Em meados da década de 1990, já fora do governo, Thatcher afirmava que o RU teria perdido a chance de resolver seu problema: um acordo de livre comércio sem entrar como membro pleno da CEE. Nas suas próprias palavras, ao se referir à fala de de Gaulle: "We may have missed the best European bus that ever came along” (Thatcher, 1995, p. 127). Por ironia da história, o Brexit trouxe o país exatamente a esse ponto.

Nas eleições de 1964 e 1966, os trabalhistas voltaram a ganhar, mas não havia menção a uma nova política com relação à CEE. No seu manifesto constava uma série de precondições para a entrada, o que na realpolitik significava ficar de fora, porque já se sabia que seriam inaceitáveis. O que mudou nos anos seguintes foi a

8 Bogdanor (2014a) lembrou que de Gaulle registrou nas suas memórias que considerava nesse momento que o pedido do RU seria uma tentativa de paralisar o processo de dentro.

9 O discurso pode ser acessado em: http://www.cvce.eu/obj/press_conference_held_by_charles_de_gaulle_by_yves_courriere_rtl_14_january_1963-en-6e48abee-7fbc-4b8b-8b87-399afaf708ea.html e http://www.fransamaltingvongeusau.com/documents/cw/CH2/7.pdf 
crise econômica, o fracasso do chamado Plano Nacional para a recuperação econômica implementado pelo governo liderado por Harold Wilson, que obrigou o país a desvalorizar sua gloriosa Libra Esterlina. Nesse contexto, o governo começou a defender que a entrada na CEE talvez pudesse ajudar na modernização da indústria e fortalecer a presença britânica no mundo. Assim, o parlamento aprovou, em 1967, por grande maioria, um novo pedido de entrada mas, desta vez, de Gaulle vetou sem sequer iniciar nova negociações. Em 1970, começa o governo conservador de Edward Heath e embora a opinião pública estivesse mais que cética ${ }^{10}$ havia, no parlamento britânico, uma ampla maioria a favor de tentar novamente uma entrada, sobretudo no contexto em que de Gaulle havia deixado a presidência. Por isso, Heat estava decidido aproveitar a janela de oportunidade para entrar na comunidade junto com a Dinamarca e a Irlanda, ampliando a CEE de seis para nove países ${ }^{11}$. Nessa negociação não havia mais o que negociar, a não ser períodos de transição para se adequar às normas vigentes. Após a conclusão do acordo, Heath conseguiu a aprovação com os votos da minoria pró-europeia dos trabalhistas, liderados por Roy Jenkins, diante de uma minoria contra no seu próprio partido. A oposição dos trabalhistas contra a entrada seguia muito mais a lógica de utilizar qualquer argumento para enfraquecer o governo conservador.

\section{DENTRO, MAS DESCONFORTÁVEL}

Em 1974, mobilizações sociais derrubaram o governo Heath, o Labour ganhou as eleições e Harold Wilson voltou a ser primeiro-ministro. Nesse momento, nasceu o primeiro referendum, em uma aposta que David Cameron pensava poder repetir 41 anos depois. O Labour começa seu governo 14 meses após a entrada na CEE e o gabinete, com lideranças notoriamente eurocéticas (em particular, James Callaghan no Ministério de Relações Exteriores, e Tony Benn, no Ministério de Energia), tinha prometido uma renegociação em torno de uma lista de pontos, sendo o principal deles, o problema da contribuição líquida excessiva devido à Política Agrícola Comum. O novo primeiro ministro da Alemanha, o socialista Helmut Schmidt, estava disposto a ajudar com uma operaçãoface-saving, fazendo algumas concessões, embora o RU continuasse o segundo maior contribuinte líquido, após a Alemanha (Young, 2000). Bogdanor, porém, relativizou os resultados desse processo e enfatizou que Wilson usou sua liderança para exagerá-los (BoGDANOR,

10 Uma pesquisa do Gallup, em abril 1970, na véspera das eleições gerais, mostrou somente 19\% a favor da entrada (YounG, 2000, p. 233)

11 Em um primeiro momento, a Noruega também participou dessa rodada, mas isso não se concretizou. 
2014c). Mesmo assim, a maioria dos deputados trabalhistas votou contra o novo acordo, que só foi aprovado com os votos dos conservadores. Pesquisas de opinião mostraram, sobretudo, desinteresse por parte da opinião pública.

O contexto era marcado, de um lado, pelo impacto do primeiro choque de petróleo, inflação, desemprego, conflito violento em torno da Irlanda do Norte, aumento do separatismo na Escócia, e, de outro, pelos interesses econômicos, na sua grande maioria, favoráveis e financiando a campanha "Britain in Europe". Nesse momento, a imprensa também era a favor da permanência. A única crítica era contra o instrumento de referendum em $\mathrm{si}^{12}$. Havia medo que uma saída pudesse piorar as coisas. A campanha "contra" era liderada pelo anti establishment. Decisivo, e muito diferente do referendum em 2016, foi a confiança nas principais lideranças dos três principais partidos que faziam campanha pela permanência do RU na CEE, prometendo que o país poderia aproveitar a abertura do mercado para sua manufatura e ter acesso aos fundos regionais (BOGDANOR, 2014c). A aposta de Wilson deu certo e 66\% votaram a favor, com 65\% de turn out t $^{13}$. A postura do governo era, porém, de distanciamento: "line of least collaboration" (Young, 2000, p. 302), e quando se posicionou contra o Sistema Monetário Europeu, o grupo dos mais pró-europeus saiu do partido e fundou o Partido Socialdemocrata (SDP na sigla inglesa) ${ }^{14}$. O Labour, por outro lado, radicalizou, e nas eleições de 1983, sob liderança do Michael Foot, defendeu abertamente a saída da CEE sem referendum, mas perdeu as eleições.

\subsection{THATCHER: A TRANSFORMAÇÃO DE PRÓ EM CONTRA}

A grande novidade que parecia, em um primeiro momento, moldar um novo caminho superando o euroceticismo do RU, era Margaret Thatcher, primeira-ministra de 1979 até 1990. Thatcher tinha colocado em pauta o problema das transferências líquidas excessivas do RU para a CEE. A partir de 1983, houve um novo ativismo na CEE. O governo Mitterand, diante do esgotamento da linha

12 Havia no RU uma vertente que considerava o instrumento de referendum não democrático por desrespeitar a soberania parlamentar. Chegou-se ao compromisso de que o Parlamento pode chamar um referendum, mas este não pode ser vinculante legalmente.

13 Pesquisa de opinião antes da conclusão da renegociação mostrava $55 \%$ pela saída e $45 \%$ pela permanência. Mas, quando a pergunta afirmava que a renegociação seria vitoriosa, somente 29\% votariam pela saída e 71\% pela permanência (BogDANOR, 2014b, p. 33).

14 Embora a Europa não tenha sido o único ponto de tensão, sem dúvida foi o que pesou mais na decisão de ruptura definitiva. Em 1988, a SDP se fundiu com o tradicional partido Liberal para formar o LibDem, contrário aos dois principais partidos, de forma consistente pró-Europa. Observe que essa posição não lhe garantiu sucesso nas eleições, embora os dois, em uma aliança eleitoral, tenham chegaram a $25 \%$ do voto popular em 1983, muito em função da radicalização do Labour sob liderança do Michael Foot. 
adotada nos primeiros dois anos do seu governo, apostava, então, nesse processo de fortalecimento da integração, em seguida liderado por Jaques Delors na presidência da Comissão Europeia. A Alemanha, com Kohl, estava igualmente decidida que precisava dinamizar o processo de integração. É nesse contexto que se dá a entrada de Espanha e Portugal, a liberalização do mercado interno, o aumento dos fundos comunitários, a reforma da política agrícola e a ampliação do voto majoritário.

No histórico encontro de Fontainebleau (França), em meados de 1984, Thatcher chegou, depois de cinco anos de negociação, a um acordo com seus pares. Ela conquistou um mecanismo de compensação financeira que considerou uma vitória e uma prova de que se o RU se pusesse firme, a Europa funcionaria. Em seguida, o RU participou ativamente da elaboração do Ato Único Europeu (Single European Act) de 1986, que previa a complementação do mercado interno até 1992. E, nesse processo, acabou aceitando paradoxalmente o voto majoritário ${ }^{15}$.

Logo, detrás dessa aparente normalização da participação britânica, reapareceram as divergências de fundo: para Delors, a complementação do mercado interno não era um fim em si, mas fazia parte de um projeto de caráter federalista de maior integração que envolveria logo em seguida a união monetária e a integração social, cultural e política. Não seria uma desregulamentação, mas uma re-regularização no âmbito europeu. Contra esse projeto de fundo, Thatcher votou contra a realização de uma conferência intergovernamental que iria resultar no Maastricht 1992. A cada passo dado para além do mercado interno, Thatcher foi se afastando mais do continente até personificar o mais ácido e agressivo euroceticismo. Fora do governo, em meados de 1990, fez campanha pela saída do RU da União Europeia.

No seu discurso no Parlamento Europeu, ao ser reconduzido como presidente da Comissão, em junho 1988, Delors fez a infeliz previsão de que em dez anos 80\% da legislação econômica e social seria europeia e não nacional. Curiosamente, esse número fictício seria usado à exaustão 28 anos depois na campanha pelo Brexit. Como se isso não bastasse para provocar o governo Thatcher, Delors fez, no mesmo ano, um discurso em defesa da legislação comunitária na área social no Congresso da central britânico, a TUC. Foi nesse contexto que Thatcher retrucou com seu histórico discurso no Colégio Europeu em Brugge, na Bélgica, conhecido

15 A complementação do mercado interno exigiria a retirada de centenas de exceções. Sem o voto majoritário os países tenderiam a usar seu direito de veto para defender os seus interesses particulares. Para Thatcher acabou sendo um cavalo de Troia. Assim o Ato Único Europeu estabeleceu não ser mais necessário um acordo unânime para as medidas com vista ao estabelecimento do mercado interno, com exceção das medidas relativas à fiscalidade, à livre circulação das pessoas e aos direitos e interesses dos trabalhadores assalariados. Além do voto majoritário, aumentou o poder da Comissão. 
como "The Brugge Speech"16. Alguns trechos evidenciaram a volta ao confronto e a ênfase nas diferenças, consideradas profundas:

...working more closely together does not require power to be centralised in Brussels or decisions to be taken by an appointed bureaucracy. Indeed, it is ironic that just when those countries such as the Soviet Union, which have tried to run everything from the centre, are learning that success depends on dispersing power and decisions away from the centre, there are some in the Community who seem to want to move in the opposite direction.... We have not successfully rolled back the frontiers of the state in Britain, only to see them re-imposed at a European level with a European super-state exercising a new dominance from Brussels (THATCHER, 1988).

Observe-se que já nesse discurso aparece a questão que se tornaria um dos temas centrais do Brexit:

... it is a matter of plain common sense that we cannot totally abolish frontier controls if we are also to protect our citizens from crime and stop the movement of drugs, of terrorists and of illegal immigrants (THAтснеR, 1988, grifos colocados).

Esse discurso foi considerado um divisor de águas no posicionamento de Thatcher, e era perfeito para reascender as chamas do euroceticismo no RU, cada vez mais distante do tempo em que Thatcher, recém-eleita como líder do partido conservador, fazia campanha pela Europa no primeiro referendum, de $1975^{17}$.

O ponto concreto que levou a uma tensão dentro do seu próprio governo e que iria contribuir para sua queda em 1990 foi a integração monetária. Delors tinha lançado um plano de unificação monetária em três estágios sendo o Mecanismo Europeu de Taxas de Câmbio (ERM na sigla inglesa) o primeiro passo. Thatcher tentou barrar a entrada no ERM por entender que isso abriria a porta para a moeda única e por acreditar, por ideologia, nas vantagens de câmbio flutuante, enquanto seus ministros e o presidente do Banco Central entenderam o ERM como forma

16 Esse discurso deu inclusive origem a uma articulação de conservadores antieuropeus como o nome de Bruges-group (https://www.brugesgroup.com).

17 Na época ela usou quatro motivos para votar pela permanência na CEE: a paz e segurança; segurança alimentar; ampliação do comercio e cooperação; uma oportunidade de representar a Commonwealth na Europa (BogDANOR, 2014b) 
de controlar a inflação ao ligar a Libra ao marco alemão. Delors com seu "big bang approach", tinha colocado o velho dilema para o governo britânico: ficar de fora ou entrar para tentar esvaziar a proposta (WALL, 2008). Em outubro 1990, depois de várias trocas de ministros, com John Major agora na Fazenda, Thatcher cedeu e o RU entrou no ERM, mais uma vez de forma tardia e tumultuada. Cabe enfatizar que a briga de Thatcher não era somente com Delors, mas também com Kohl, uma vez que ela se opôs também firmemente à unificação da Alemanha, levantando o temor da síndrome de uma Europa germânica, ao invés de uma Alemanha europeizada (a chave política churchiliana). De seu lado, Kohl entendeu que a unificação deveria ser acompanhada de um processo de ampliação da integração europeia para encontrar menos resistências e por isso apoiou o ativismo de Delors. Este anunciou, em seguida, que a moeda única seria uma realidade até o ano 2000, o que provocou duas reações no RU: uma fala de Thatcher dizendo que o Parlamento britânico jamais concordaria e a famosa capa do jornal The Sun (ver figura 1):

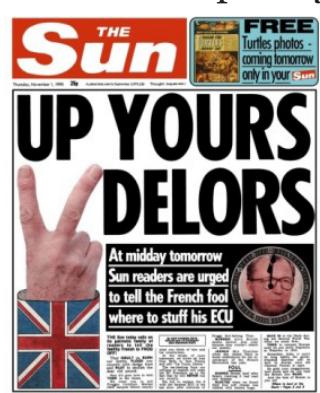

Figura 1. Capa do Jornal the Sun, 1/11/1990.

Em 2012, já aposentado, Delors tende a concordar com de Gaulle e Thatcher ao declarar, em uma entrevista ao jornal Daily Mail: 'If the British do not follow the tendency towards more integration in the European Union, we can anyway stay friends, but in another way.' E sugeriu, nesse mesmo momento, que o RU poderia negociar um acordo 'like that of the European economic area' or a 'free trade agreement' (BLACK, 2012). Quatro anos mais tarde, o povo britânico concordou finalmente com uma proposta de Delors ao votar pelo Brexit.

Thatcher, de seu lado, com o passar dos anos, radicalizou cada vez mais sua posição anti-Europa e, em 2002, publicou uma dura posição a respeito:

That such an unnecessary and irrational project as building a European super state was ever embarked on will be seen in future years to be perhaps the greatest folly of the modern era. And that Britain, with her traditional strengths and global destiny, should ever have been part of it will appear a political error 
of historic magnitude. There is, though, still time to choose a different and a better course (THATCHER, 2002).

É bastante provável que, se tivesse viva e ativa em 2016, ela teria feito campanha pelo Brexit.

\subsection{MAASTRICHT: VITÓRIA DE PERNAS CURTAS}

Depois da queda da Thatcher, coube a John Major (1990-1997) negociar o Tratado de Maastricht. Ele seguiu a estratégia de ficar dentro, mas com uma perna fora, negociando os famosos “opt-outs": o RU não seria obrigado a entrar no Euro e estava fora dos acordos sobre políticas sociais. Parecia em um primeiro momento uma vitória. A capa do Daily Mail expressou os sentimentos iniciais: "He went. He stood firm. And he prevailed" (Young, 2000, p. 433). Parecia que se tinha conseguido "the comfortable both ways" e este entusiasmo ajudou Major a ganhar as eleições em 1992. Mas, logo em seguida, dois fatores mudaram os ânimos britânicos: um referendum na Dinamarca rejeitou Maastricht e, pior, na véspera do referendum na França, os mercados começaram uma especulação contra a Libra Esterlina, derrubando-a e obrigando o país, dois anos após ter entrado tardiamente, a sair do ERM, o que foi considerado uma humilhação nacional ${ }^{18}$. Isso reforçou muito os eurocéticos e houve pressão para a realização de um referendum também no RU, o que Major rejeitou ${ }^{19}$. Maastricht significou para os eurocéticos um inaceitável aumento de poder da Comissão e do Parlamento Europeu. A aprovação do governo Major caiu de 43\% para 29\% para nunca mais se recuperar até sua dramática derrota nas eleições de 1996 contra Tony Blair (BogdANOR, 2014c). Vale destacar o reposicionamento do então Ministro de Finanças, Norman Lamont, que tinha sido um defensor da entrada do RU no ERM, mas saiu do governo depois da desvalorização forçada e passou, então, a defender o óbvio: ou o RU aceitava o avanço do federalismo ou precisaria renegociar algum tipo de saída. Não haveria como negociar um via intermediária, e Lamont optou pela segunda, ficando ao lado da nova onda de euroceticismo dos conservadores caracterizada como "neo-Tatcherite revival" (Young, 2000, p. 442-443).

18 Esse episódio é conhecido na história política britânica como "Black Wednesday", embora os eurocéticos logo começassem a falar em "White Wednesday” porque o RU teria se libertado das amarras de Bruxelas.

19 Thatcher, no House of Lords, defendeu a realização de um referendum e disse que votaria contra o Tratado de Maastricht, que ela considerou "A Treaty too far" (BogDANor, 2014c, p.45). Blair não se comprometeu somente com um referendum caso o RU entrasse no Euro. 
O próprio Major arrastou seu mandato, se aproximando do euroceticismo e se manifestando publicamente contra o perigo de criação de um superestado que se sobrepusesse à soberania do Parlamento britânico (MAJOR, 1993). Vale observar que, em 1996, a Europa quase não foi discutida durante a campanha, por um motivo simples: os conservadores não queriam expor sua divisão e o Labour não queria se comprometer. Já no governo, Tony Blair, que tinha iniciado sua carreira como parlamentar em uma plataforma antieuropeia, apresentou-se como pró-europeu enquanto parte da sua agenda positiva ("constructive engagement") e modernizadora. Blair era inicialmente a favor da entrada do RU no Euro, mas teria se comprometido com o referendum e sabia que em um processo interno de votação, isso não passaria. Além disso, havia uma forte oposição no seu partido à adoção da moeda única. Assim, o governo Blair acabou respeitando o pacto de Major e, na tradição churchiliana, tentou garantir presença e voz na Zona do Euro, mesmo sem ser membro, considerando os efeitos das decisões do Eurogrupo (EuroGroup) sobre a economia britânica.

O Eurogrupo iniciou suas reuniões mensais informalmente em 1998, mas teve seu papel formalizado no Tratado de Lisboa, que entrou em vigor em 2009. Ele é composto pelos Ministros de Finanças dos países que adotaram o Euro, o Comissário Europeu para assuntos econômicos e financeiros e o presidente do Banco Central Europeu. Nessas reuniões, se discute, na prática, a coordenação das políticas econômicas. O RU, mais uma vez, ficou de fora, sem poder de frear os avanços que temia no processo de integração europeu. De fato, estava se configurando o que Blair queria evitar: a Europa de duas velocidade ${ }^{20}$. A repercussão da crise financeira global de 2008 provocou um aprofundamento do processo de integração na direção de uma união fiscal e bancária. David Cameron (2010-2016) tentou ainda liderar os países que não estavam na Zona do Euro, mas, com exceção da Dinamarca, os demais estavam se preparando, justamente, para adotar a moeda única (BogdANor, 2014c). O clima era de aumento de euroceticismo, sobretudo entre os conservadores: se o RU não fazia parte do núcleo duro que na prática estava tomando as decisões, talvez fosse melhor ficar de fora mesmo.

\subsection{TRISTE FIM DE CAMERON}

Como já dito, David Cameron queria repetir a manobra de Harold Wilson de 1975. Ao chamar um referendum poderia impor sua liderança no partido conser-

20 Cabe lembrar também o distanciamento provocado entre o governo Blair e os governos da Alemanha e França ao apoiar incondicionalmente o governo Bush na guerra no Iraque que se iniciou em 2003 e que encontrou forte oposição dos presidentes Jacques Chirac e Gerhard Schroeder. 
vador diante do euroceticismo, da mesma forma que Wilson o fez com as eurocéticos no partido trabalhista da época. O jogo era o mesmo: anunciar uma gloriosa guerra contra Bruxelas, conquistando concessões supostamente significativas que mostrariam que, nessa nova situação, valeria a pena continuar. Ao anunciar o referendum em janeiro de 2013, não havia nenhuma pressão da opinião pública ou do Parlamento pela realização do referendum. Foi o próprio Cameron que resolveu colocar a possibilidade de sair da UE novamente na agenda política, o que custaria sua carreira política. Em fevereiro de 2016, chegou-se ao novo acordo com concessões mínimas: o New Settlement for the United Kingdom within the European Union. O problema era que, em 1975, o tema da Europa não era tão importante em si e o que Wilson quis mostrar foi uma renegociação das contribuições do RU, o que não implicava emendar o Tratado de Roma. Acontece que, em 2014 e 2015, depois de ter anunciado o referendum, o tema central nos debates em toda a Europa girava em torno dos fluxos migratórios, sobretudo diante da crise humanitária de 2015 , ano em que chegou quase ao patamar de um milhão de refugiados somente na Alemanha. Seria impossível negociar qualquer alteração na política migratória sem emendar o Tratado de Roma, levando em conta que o RU já estava de fora do Acordo de Schengen ${ }^{21}$. Aqui, identificamos claramente a conjuntura que interage com os fatores do path dependency, gerando um resultado imprevisível. Além do impacto do debate sobre migração, havia outra diferença fundamental em relação ao contexto do primeiro referendum: o RU não havia escapado da tendência a uma crescente distância que se criara entre as elites políticas e a base social ${ }^{22}$. E, por fim, mas não menos importante, houve o impacto da crise financeira global que acentuou as diferenças socioeconômicas e eliminou as expectativas de uma parte significativa da antiga base eleitoral dos trabalhistas. Mas, justamente, esses fatores conjunturais - a migração, a desconfiança das elites políticas e os impactos da crise financeira global -, que também estavam presentes na Europa continental, tiveram o impacto que tiveram no RU porque essa conjuntura se cruzou com uma trajetória

21 O Acordo foi firmado em 1985 fora da estrutura da CEE e criou o Espaço Schengen para permitir a livre circulação de pessoas dentro dos países signatários, sem a necessidade de apresentação de passaporte nas fronteiras. Em 1990 foi firmado a Convenção de Schengen e em 1999 ela foi incorporada à legislação europeia no Tratado de Amsterdam. Em 2016, envolveu todos os países da União Europeia, com exceção do RU, Irlanda, Romênia, Bulgária e Croácia, mas com a participação de alguns países não membros (Suíça, Noruega, Islândia e Listenstaine) e alguns outros.

22 O recém-eleito novo líder dos Trabalhistas, Jeremy Corbyn, entendeu o risco de se identificar demais com a bandeira de oposição ao Brexit e, apesar de seguir a linha oficial, não se envolveu de forma enfática na campanha. Essa atitude gerou críticas dos demais partidos pró-Europa e da maioria dos parlamentares de seu próprio partido. Mas rendeu frutos nas eleições em junho 2017, quando conseguiu contrariar as expectativas e recuperar a confiança de uma parte da base do partido que tendia a se desiludir cada vez mais. 
tipicamente britânica de euroceticismo estrutural, que diverge muito das trajetórias na Europa continental. Gowland e Turner caracterizam essa relação entre o RU e a UE como sendo marcado por "deeply rooted ambivalence" e "hestitant, reactive approach" (Gowland; TuRner, 1998, p. xi).

Um fator que não pode ser explorado em detalhes neste artigo é a mudança na fração dominante do capital nesse processo. Na década de 1970, quando houve o primeiro referendum, era ainda a indústria que predominava, tanto de capital nacional, como as multinacionais predominantemente de capital estadunidense. A defesa do RU na CEE era baseada na ideia de um acesso aos mercados pela manufatura e a possibilidade para as multinacionais de racionalizar a sua estrutura de produção, fornecimento e distribuição. Esses interesses poderiam, por meio de negociações sindicais, também resultar positivos para os trabalhadores, na medida em que houvesse a perspectiva de geração de emprego e renda no RU. Pelo menos assim era a visão das forças políticas hegemônicas no movimento sindical e no movimento trabalhista da época. Já depois do thatcherismo e com a tendência mundial de financeirização do capitalismo, a fração dominante tornou-se claramente o capital financeiro transnacional em torno da City of London. E esses interesses eram vistos como antagônicos aos interesses gerais dos trabalhadores por grande parte dos movimentos sindicais e, sobretudo, por aqueles que tinham sofrido as consequências da crise global. E, sem dúvida, o setor financeiro conseguiu aproveitar muito bem a ambivalência de estar fora das amarras do BCE, mas com acesso ao mercado europeu, operando como ponte entre os mercados de Nova York, Shanghai/Hong Kong e a Europa continental. É muito provável que o apoio desse setor à permanência na União Europeia tenha contribuído para fortalecer o euroceticismo em parte das camadas populares.

\section{CONSIDERAÇÕES FINAIS}

Ao reconstruir a trajetória do RU diante do processo de integração europeia, identificamos que a decisão britânica de não participar do Plano Schuman e, por conseguinte, ficar ausente das primeiras discussões sobre o formato da integração econômica europeia pode ser considerada como o evento contingente que influenciaria de modo decisivo os eventos subsequentes. A estratégia de construção de uma área de livre comércio europeia- a EFTA prevista no Plano G - veio tarde demais e reforçou a ideia de incompatibilidade de visões entre a ilha e o continente. A entrada do UK na CCE em 1973 foi sem entusiasmo e em um momento em que não havia ganhos econômicos visíveis para a população. A tentativa de Thatcher de direcionar novamente a integração para uma área de livre comércio, sugerindo que 
o Ato Único Europeu deveria ser a parada final do processo, subestimou completamente a dinâmica no continente. A ideia de uma relação living-together-apart de Major e Blair, com os opt-outs que consolidaram a excepcionalidade britânica, parecia um novo equilíbrio, mas as tensões se acumularam diante de uma nova dinâmica em torno do Euro.

Essa análise histórica de tipo path dependency mostra, portanto, que no RU o euroceticismo tem raízes muito mais profundas do que as do euroceticismo surgido nos países do continente no início da década de 2010, já no contexto dos desdobramentos da crise financeira global. Cabe aqui enfatizar o bombardeio de discursos inflamados, repletos de ceticismo, que gerações de britânicos escutaram de lideranças dos dois principais partidos (trabalhistas e conservadores) e mais recentemente da direita radical com o Partido de Independência do Reino Unido (na sigla inglesa, UKIP). Nada disso nunca existiu no continente. A defesa de outro lado sempre seria na linha de um oportunismo e um realismo: "if not the EEC, what?". Ou seja, o mal menor. Agora, depois do Brexit, cabe ao governo britânico negociar dois acordos: o de separação e o de um novo relacionamento. Este último será o mais difícil, porque o dilema continua: incomodado dentro, mas sem querer ficar de fora. O governo May quer encontrar um acordo para estabelecer uma relação living apart together.

\section{REFERÊNCIAS BIBLIOGRÁFICAS}

BLACK, James. "Britain would be better off leaving Europe': Thatcher rival Jacques 'Up Yours Delors' makes massive euro u-turn (and it's only 22-years too late)”. Daily Mail, Londres, 28 de Dezembro de 2012. Disponível em: http://www.dailymail.co.uk/news/ article-2254299/Thatcher-rival-Jacques-Up-Yours-Delors-makes-massive-euro-uturn-22-years-late.html Acesso em: 20 de Maio de 2017.

BLYTH, Mark; MATTHIJS, Matthias. Black Swans, Lame Ducks, and the mystery of IPE's missing macro-economy. Review of International Political Economy. v. 24, n.2, p. 203-231, 2017.

BOGDANOR, Vernon. The Decision to Seek Entry into the Common Market. Gresham College, 2014a. Disponível em: https://www.youtube.com/watch?v=0793B8mr4-c Publicado em 29/01/2014. Acesso em: 20 de maio de 2017.

. The referendum in Europe, 1975. Gresham College, 2014b. Disponível em : https://www.youtube.com/watch?v=U_4vNtSqahk Publicado em 22 de maio de 2014. Acesso em: 20 de maio de 2017. 
"The Growth of Euroscepticism". Grasham College, 2014c. Disponível em: https://www.youtube.com/watch?v=LiyNr_LALlU Publicado em 17 de junho de 2014. Acesso em: 21 de Maio de 2017.

CAMPS, Miriam. [1964] Britain and the European Community 1955-1963. Princeton: Princeton University Press, 2017.

COSTA, Fernando Nogueira. "Sequências Reativas, Cíclicas e de Feedback Negativo. Blog do Fernando Nogueira da Costa, Teoria Econômica”. Postado 29/o3/2015. Disponível em: https://fernandonogueiracosta.wordpress.com/2015/03/29/ sequencias-reativasciclicas-e-de-feedback-negativo/. Acesso em: 22 de maio de 2017.

GOWLAND, David; TURNER, Arthur. Britain and European Integration, 1945-1998: A Documentary History. London, NY: Routledge, 2000.

GROSS, Stephen. The Brexit Vote, One Year Later. The Historical Roots of the Decision to Leave the EU. Foreign Affairs, June 2016.

MAHONEY, James. Path Dependence in historical sociology. Theory and Society, v.29, p. 507-548, 2000.

MAJOR, John. Europe. The Economist, 25 de setembro de 1993. Disponível em: http:// www.johnmajor.co.uk/page2380.html. Acesso em: 20 de Maio de 2017.

NOOTEBOOM, Bart. Path-dependence of Knowledge: Implications for the Theory of the Firm. In: MAGNUSSON, Lars; OTTOSSON, Jan. Evolutionary Economics and Path Dependence. Cheltenham: Edward Elgar, p. 57-78, 1997.

SEWELL, William. Three Temporalities: Toward a Sociology of the Event. Working Paper 58. University of Chicago, Outubro, 1990.

THATCHER, Margaret. The Bruges Speech. The College of Europe, September 20, 1988.

Disponível: http://www.margaretthatcher.org/document/107332. Acesso em: 20 abril de 2017.

. Statecraft. Strategies for a changing world. New York: HarperCollins, 2002. The Path to Power. London: HarperCollins, 1995.

WALL, Stephen. A Stranger in Europe. Britain and the European Union from Tatcher to Blair. Oxford: Oxford University Press, 2008.

YOUNG, Hugo. This Blessed Plot. New York: Overlook Press, 1998. 